\title{
Long-Term Potentiation in Distinct Subtypes of Hippocampal Nonpyramidal Neurons
}

\author{
Gianmaria Maccaferri and Chris J. McBain \\ National Institute of Child Health and Human Development, Laboratory of Cellular and Molecular Neurophysiology, \\ Bethesda, Maryland 20892-4495
}

We have investigated NMDA receptor-dependent long-term potentiation (LTP) in distinct subtypes of nonpyramidal neurons of the CA1 hippocampus using induction protocols that permitted the differentiation between a direct form of LTP and plasticity resulting simply from the "passive propagation" of LTP occurring on CA1 pyramidal neurons. Two types of stratum (st.) oriens/ alveus interneurons received passive propagation of synaptic potentiation via the recurrent collaterals of CA1 pyramidal cells, but neither subtype possessed direct plasticity. In st. radiatum, two distinct classes of cells were observed: st. radiatum interneurons that showed neither direct nor propagated forms of synaptic plasticity, and "giant cells" for which EPSPs were robustly potentiated after a pairing protocol. This potentiation is similar to the LTP described in pyramidal cells, and its induction requires NMDA receptor activation. Thus, a large heterogeneity of synaptic plasticity exists in morphologically distinct neurons and suggests that complex changes in the CA1 network properties will occur after the induction of LTP.

Key words: hippocampus; interneurons; LTP; plasticity; GABAergic; CA1
Synaptic plasticity of the CA1 subfield of the rat hippocampus has been extensively studied and characterized in pyramidal cells (Bliss and Collingridge, 1993; Malenka and Nicoll, 1993; Lisman, 1994). Although many issues still are under debate (Kullmann and Siegelbaum, 1995), the mechanisms involved in the induction of long-term potentiation (LTP) and long-term depression (LTD) have been elucidated (Bliss and Collingridge, 1993; Malenka, 1994). Both forms of plasticity require the activation of postsynaptic NMDA receptors (NMDARs) and an elevation of intracellular calcium levels (Collingridge et al., 1983; Malenka et al., 1988, Dudek and Bear, 1992; Mulkey and Malenka, 1992), which lead to phosphorylation or dephosphorylation processes (Malinow et al., 1988; Malenka et al., 1989; Mulkey at al, 1993; Lisman, 1994).

At the level of the hippocampal network, the net flow of information in the CA1 region is strongly modulated by the action of the nonpyramidal neurons, the cell bodies of which are distributed throughout all layers of the hippocampus (Lacaille et al., 1987, 1989; Lacaille and Schwartzkroin, 1988a,b; Buhl et al., 1994; Sik et al., 1994, 1995; Cobb et al., 1995; Maccaferri and McBain, 1995) (for review, see Freund and Buzsaki, 1996). The vast majority $(\sim 90 \%)$ of these cells have been shown to be glutamate decarboxylase (GAD)- positive inhibitory interneurons (Woodson et al., 1989), the axons of which target different domains of the pyramidal cell dendritic tree (Gulyás et al., 1993; Buhl et al., 1994; Sik et al., 1995). Therefore, the possibility of additional synaptic plasticity occurring in nonpyramidal cells would greatly increase both the power and the level of complexity of signal processing in the CA1 subfield. Indeed, several reports have shown that after tetanic stimulation, changes occur in (1) evoked nonpyramidal cell firing probability (Buzsaki and Eidelberg, 1982), (2) IPSP ampli-

\footnotetext{
Received April 30, 1996; revised June 4, 1996; accepted June 6, 1996.

We thank Dr. Vittorio Gallo for his constructive criticism of this manuscript.

Correspondence should be addressed to Dr. Chris J. McBain, Unit on Cellular and Synaptic Physiology, Laboratory of Cellular and Molecular Neurophysiology, Room 5A72, Building 49, National Institute of Child Health and Human Development, 9000 Rockville Pike, Bethesda, MD 20892-4495.

Copyright (C) 1996 Society for Neuroscience $0270-6474 / 96 / 165334-10 \$ 05.00 / 0$
}

tudes recorded on pyramidal cells (Xie and Sastry, 1991; Morishita and Sastry, 1991), and (3) EPSP or EPSC amplitudes recorded in interneurons (Taube and Schwartzkroin, 1987; Stelzer et al., 1994; Ouardouz and Lacaille, 1995). In addition, however, synaptic depression occurring at the Schaffer collateral-pyramidal neuron synapses can "passively propagate" to interneurons of the st. oriens/alveus and influence the excitatory drive of these cells (Maccaferri and McBain, 1995). The contribution of passive propagation to other reported forms of inhibitory neuron "plasticity" largely remains untested.

Most of the previous studies have used experimental paradigms that involve tetanic stimulation to induce LTP. The use of a tetanic stimulation protocol, however, does not distinguish between direct or passively propagated forms of synaptic plasticity. In the present paper, we have investigated the possible induction of NMDAR-dependent (Sah et al., 1990; Perouansky and Yaari, 1993) LTP in different subtypes of nonpyramidal cells using protocols that differentiate between a direct form of LTP and its passive propagation from the recurrent collaterals of CA1 pyramidal cells. Our results show a heterogeneity of plastic responses that depend on the cell type and its relative position in the hippocampal network.

\section{MATERIALS AND METHODS}

Slice preparation. The methods for preparation of hippocampal slices were similar to those described previously (Maccaferri and McBain, 1995). Briefly, transverse hippocampal slices (300-350 $\mu \mathrm{m}$ thick) were cut on a vibratome (Oxford series 1000) from Sprague-Dawley rats postnatal day (P) 16-22 after isoflurane anesthesia. Slices were incubated in a solution containing (in mM): $130 \mathrm{NaCl}, 24 \mathrm{NaHCO}_{3}, 3.5 \mathrm{KCl}, 1.25$ $\mathrm{NaH}_{2} \mathrm{PO}_{4}, 1 \mathrm{CaCl}_{2}, 3 \mathrm{MgSO}_{4}, 10$ glucose saturated with $95 \% \mathrm{O}_{2} / 5 \% \mathrm{CO}_{2}$, $\mathrm{pH} 7.4$, and held at room temperature and allowed a recovery period of at least $1 \mathrm{hr}$ before use.

Electrophysiological methods. All recordings were performed at room temperature $\left(\sim 22-26^{\circ} \mathrm{C}\right)$ using an extracellular medium of the following composition (in mM): $130 \mathrm{NaCl}, 24 \mathrm{NaHCO}_{3}, 3.5 \mathrm{KCl}, 1.25 \mathrm{NaH}_{2} \mathrm{PO}_{4}, 2.5$ $\mathrm{CaCl}_{2}, 1.2 \mathrm{MgSO}_{4}, 10$ glucose, saturated with $95 \% \mathrm{O}_{2} / 5 \% \mathrm{CO}_{2}, \mathrm{pH}$ 7.4. Synaptic responses were evoked by stimulation of st. radiatum afferents (100-150 $\mu \mathrm{sec}$ duration, $20-300 \mu \mathrm{A}$ intensity) via a constant current 
isolation unit (A360, World Precision Instruments, Sarasota, FL) connected to a concentric bipolar electrode (Frederick Haer and Company). Stimulus intensities were chosen that evoked a subthreshold EPSP during the baseline collection period. Extracellular field population spikes (fPS) were recorded in CA1 st. pyramidale using a whole-cell pipette filled with extracellular solution using an Axoclamp 2B (Axon Instruments, Foster City, CA) in bridge mode. Bicuculline methobromide $(1 \mu \mathrm{M})$ was routinely added to the extracellular medium to reduce inhibition. Recordings from single cells were performed using either perforated-patch (Korn et al., 1991) or whole-cell (Hamill et al., 1981; Edwards et al., 1989) recording configurations with an Axopatch 1-D amplifier (Axon Instruments) in current-clamp mode. Tight-seal $(>1 \mathrm{G} \Omega)$, whole-cell recordings were performed under visual control using a $40 \times$ Hoffman, waterimmersion, objective (Zeiss). Positive pressure was applied to the inside of the electrode while penetrating the slice (Blanton et al., 1989). Using this recording arrangement, it was possible to clearly identify the cell body of the target cell and its proximal dendrites. Horizontal and vertical st. oriens/alveus interneurons (OAIs) were easily distinguished because of the orientation of their cell bodies and dendrites. St. radiatum "giant cells" (RGs) also had a stereotypical appearance, and were selected because of their triangular cell body with two main diverging dendritic shafts emerging from the soma (see Fig. 5). Whole-cell electrodes had a resistance $\sim 3 \mathrm{M} \Omega$ when filled with (in $\mathrm{mM}$ ): $100 \mathrm{~K}$-gluconate, 0.2 EGTA, 1.5-5.0 $\mathrm{MgCl}_{2}, 0-7.5 \mathrm{NaCl}, 2.0 \mathrm{ATP}_{2} \mathrm{Na}, 0.3 \mathrm{GTPNa}, 40$ HEPES, pH 7.2-7.3. Biocytin $(0.2-0.4 \%)$ was routinely added to the recording electrode to allow post hoc morphological processing of the recorded cell. The perforated-patch recording configuration was achieved in a two-step procedure. First, a regular cell-attached seal on the target cell was obtained with electrodes filled with the following solution (in mM): 100 K-gluconate, 10 tetraethylammonium chloride (TEA), 40 HEPES, 0.2$0.4 \%$ biocytin. Second, to obtain the perforated-patch configuration, an identical solution containing gramicidin $(20 \mu \mathrm{g} / \mathrm{ml})$ (Kyrozis and Reichling, 1995) was perfused into the tip of the electrode, using a commercially available intracellular perfusion kit $\left(2 \mathrm{PK}^{+}\right.$, Adams and List, Westbury, NY). Perforated-patch configuration usually was achieved $20-40$ min after perfusing the electrode tip, and the series resistance (range, 30-100 M $\Omega$ ) was continuously monitored using electrotonic current injection. The inclusion of the potassium channel blocker TEA in the intracellular solution facilitated detection of recordings in which spontaneous breakthrough of the seal probably had occurred. Consequently, cells were rejected when a sudden decrease in series resistance and/or a broadening of the action potential duration, caused by TEA entry into the cell, was observed. At the end of each experiment, breakthrough into a whole-cell configuration was attempted to permit introduction of biocytin into the cell under study. This manipulation allowed post hoc morphological identification of the cells from which recordings were made. No differences were observed in data obtained from either whole-cell or perforated-patch recording configurations; therefore, in experiments in which both recording configurations were used, data were pooled together in the summary plots. All the data are expressed as percentage of control as mean \pm SEM. When appropriate, Student's $t$ test was applied.

Data analysis. Data were acquired and digitized with an A/D interface (Digidata 1200, Axon) and analyzed by use of commercial software (pCLAMP6, Axon) (Origin 3.73, Microcal). EPSP initial slopes were calculated using a least-squares regression to minimize the contribution of voltage-activated conductances. In experiments in which the EPSP was contaminated by a spike after LTP induction, care was taken to exclude the upstroke of the action potential during analysis. fPS amplitudes were measured as the excursion between the first positive and the first negative peak. Traces are shown as averages of 5-10 consecutive recordings. The measurements obtained from every six traces were averaged to produce a single value for every minute data point.

All averaged values reported were calculated from data collected over a $5 \mathrm{~min}$ period that was between 10 and $15 \mathrm{~min}$ after pairing induction protocol and 25 and 30 min after tetanus protocol. Data were compared to the averaged value obtained from the $5 \mathrm{~min}$ immediately before the relevant induction protocol. For simplicity, all data were expressed as a percentage relative to the initial $5 \mathrm{~min}$ baseline, which was arbitrarily set at $100 \%$.

LTP-inducing protocols. During the course of an experiment, cells were held at -70 to $-75 \mathrm{mV}$, using constant current injection. Synaptic events were evoked at a control frequency of $0.1 \mathrm{~Hz}$. LTP was induced by means of two protocols: pairing and tetanization. The pairing protocol consisted of a $1 \mathrm{~Hz}$ stimulation of $60 \mathrm{sec}$ duration, coupled to cell depolarization to approximately $-20 \mathrm{mV}$, using current injection. During the pairing protocol, the amplitude of the recorded EPSP was monitored and was always observed to decrease dramatically, indicating that significant depolarization of membrane potential was achieved. The tetanization protocol consisted of a train of four separate tetani $(100 \mathrm{~Hz}, 1 \mathrm{sec}$ duration) delivered to st. radiatum fibers every $15-30 \mathrm{sec}$.

Histological methods. Slices were fixed in $4 \%$ paraformaldehyde $(>24$ $\mathrm{hr}$ ), immersed in PBS containing 30\% sucrose, and resectioned into $\sim 150$ $\mu \mathrm{m}$ sections on a freezing microtome. Biocytin staining was revealed using an avidin/horseradish peroxidase reaction (Vectastain ABC, standard kit) and enhanced using $1 \% \mathrm{NiNH}_{4} \mathrm{SO}_{4} / 1 \% \mathrm{CoCl}_{2}$ to permit visualization of the axon. Slices were mounted and dehydrated on gelatincoated glass slides for camera lucida reconstruction.

\section{RESULTS}

It is useful to first address some technical issues relevant to the interpretation of the data presented in this study. NMDARdependent LTP can be induced in pyramidal cells either by pairing low-frequency stimulation with cell depolarization or by tetanic stimulation of the afferent pathway. Both methods have proven reliable induction protocols and yield comparable results in CA1 pyramidal neurons. However, the same protocols cannot be regarded as equivalent when applied to interneurons, which may receive both innervation from the afferent pathway undergoing stimulation and inputs from the recurrent collaterals of CA1 pyramidal cells. The use of a pairing procedure, therefore, allows induction of LTP only in the cell under study, the NMDARs of which are relieved of $\mathrm{Mg}^{2+}$ blockade during depolarization (Mayer et al., 1984; Nowak et al., 1984), and not in the surrounding pyramidal cells which undergo, in contrast, LTD resulting from the $1 \mathrm{~Hz}$ stimulation (Mulkey and Malenka, 1992). Therefore, application of the pairing procedure to interneurons receiving innervation from CA1 pyramidal cells will dissociate direct LTP from passive propagation of the LTD occurring at synapses on pyramidal cells. Consequently, any pairing-induced LTP observed in a single cell cannot result from the passive propagation mechanism and can be explained only by a direct mechanism. In contrast, tetanic stimulation may simultaneously induce LTP, both in the interneuron under study and in the pyramidal cell population. Therefore, LTP observed in a nonpyramidal cell after tetanization has ambiguous origins, possibly arising from a direct mechanism or as passive propagation from principal cells. Thus, to determine unequivocally the site of plasticity, we have applied both protocols sequentially to the cell under study.

Another technical issue that may be useful to discuss here is the validity of the patch-clamp technique in the study of "in vitro" synaptic plasticity. Although direct LTP has been widely recorded in pyramidal cells under whole-cell conditions, washout of cytoplasmic components necessary to induce LTP has been reported to occur after $\sim 30$ min (Kato et al., 1993) (however, see also Clark and Collingridge, 1995). In the present manuscript, we have combined both perforated-patch (Korn et al., 1991) and wholecell recording techniques. In the experiments in which whole-cell recording techniques were used, we reduced the baseline recording before the pairing induction protocol to $5 \mathrm{~min}$. Moreover, the data obtained under perforated-patch recording conditions, in which no washout can occur, are in complete agreement with the whole-cell results.

\section{OAls}

Recordings were made from two distinct cell types in the st. oriens/alveus, which have been described previously as horizontal and vertical (Schlander and Frotscher, 1986; McBain et al., 1994; Blasco-Ibáñez and Freund, 1995; Maccaferri and McBain, 1995; Zhang and McBain, 1995). Typically, as shown in Figure 1, the 


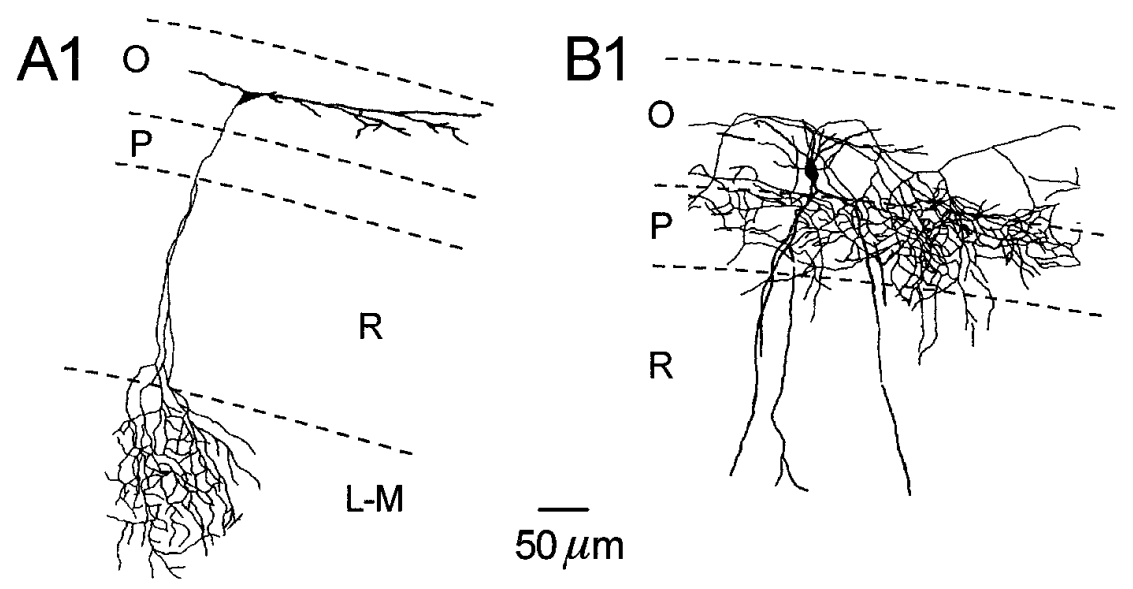

Figure 1. Horizontal and vertical OAIs can be differentiated both morphologically and electrophysiologically. A typical horizontal OAI is shown (A1); note its dendritic tree confined to st. oriens $(O)$ and its axonal projection to st. lacunosum/moleculare $(L-M)$. In $A 2$, the result from a representative double-recording experiment is shown. After stimulation of st. radiatum $(R)$ afferents, note that the peak of the fPS (upper trace) precedes the onset of the EPSP (lower trace) $(+3.2$ $\mathrm{msec})$. B1 shows a vertical interneuron; note the dendritic arborization in both st. oriens and radiatum and the axonal plexus largely restricted to st. pyramidale $(P) . B 2$ shows a biphasic EPSP recorded from a vertical cell after afferent stimulation; note the early component preceding the fPS, whereas a second component follows it $(-3.9$ and $+2.8 \mathrm{msec}$, respectively).
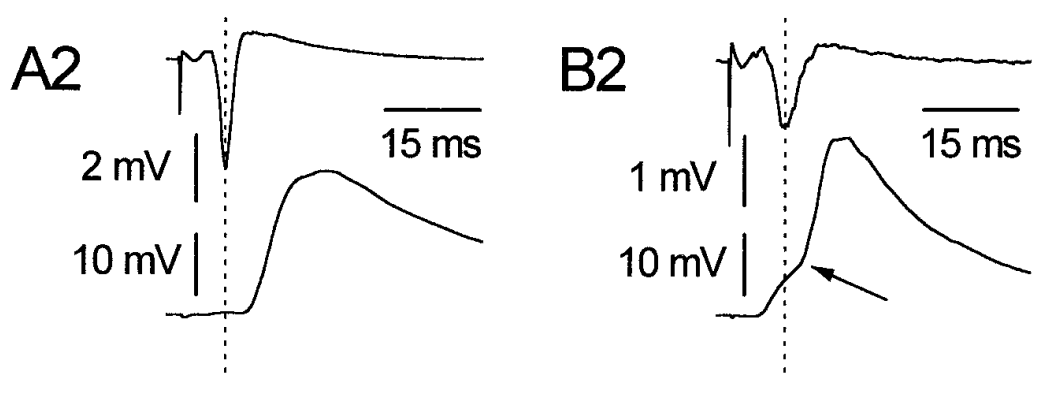

axons of horizontally oriented interneurons ramified in st. lacunosum/moleculare and had dendritic trees confined to the st. oriens/alveus. In contrast, vertically oriented cells had axons that typically innervated st. pyramidale and possessed dendrites that projected into st. radiatum. EPSPs from both types of cells were recorded using perforated-patch and whole-cell patch-clamp techniques after stimulation of st. radiatum afferents. Simultaneous monitoring of CA1 pyramidal cell activity was made using an extracellular electrode placed in st. pyramidale. As is clearly shown in Figure 1, the onset of the EPSP recorded from horizontal cells was preceded by the peak of the fPS, $(n=9)$. This result confirms our previous report suggesting a pure feedback role for horizontal interneurons (Maccaferri and McBain, 1995) (see also Blasco-Ibáñez and Freund, 1995). In contrast, the onset of the EPSP in vertical interneurons always preceded the fPS peak $(n=$ 9). Moreover, in eight of nine vertical cells, a clear biphasic synaptic response was discernible (arrow in Fig. 1). These data are consistent with both a feedforward excitation of vertical OAIs by Schaffer collateral inputs and a feedback innervation of the OAIs by the recurrent collaterals of CA1 pyramidal neurons (Lacaille et al., 1987). It should be noted, however, that our data support only feedforward excitation of vertically and not of horizontally oriented interneurons.

Although we have reported previously the absence of a direct LTD in horizontal OAIs (Maccaferri and McBain, 1995), no detailed study was performed to analyze the possible induction of LTP in these cells. We therefore first investigated the effect of tetanic stimulation and the possible involvement of NMDARs in LTP induction in horizontal OAIs. As shown in Figure 2, tetanic stimulation in the presence of D-AP5 $(50 \mu \mathrm{M})$ was ineffective in inducing LTP either of the fPSs $(A 1)$ or the simultaneously recorded interneuron EPSPs
(A2) $(117.5 \pm 14.1 \%$ for fPS, $n=6$, NS and $106.2 \pm 7.3 \%$ for EPSP, $n=6$, NS). However, after washout of D-AP5, LTP could be obtained in both recordings $(198.2 \pm 36.4 \%, n=6, p<0.05$ for fPS; $155.2 \pm 13.1 \%, n=6, p<0.05$ for EPSP). This result suggests that horizontal OAIs undergo a LTP process similar to that described in pyramidal neurons, or alternatively, the observed activity may reflect passive propagation of LTP induced at synapses onto CA1 pyramidal cells. In the first hypothesis, NMDARs located on the interneuron would be responsible for the induction of plasticity, whereas in the case of passive propagation, NMDARs on pyramidal cells would be involved.

To discriminate between these two possibilities, we attempted to induce LTP in horizontal interneurons by means of a pairing protocol. The pairing protocol matches low-frequency stimulation $(1 \mathrm{~Hz})$ with cell depolarization (approximately $-20 \mathrm{mV}$ ), as reported previously for CA1 pyramidal cells (Gustafson et al., 1987; Malinow and Tsien, 1990; Malinow, 1991; Schuman and Madison, 1994; Isaac et al., 1995; Liao et al., 1995). This pairing protocol has the advantage of inducing LTP only in the cell under study. The other cells, which are not depolarized by current injection through the recording pipette, will be subjected only to the $1 \mathrm{~Hz}$ stimulation at their resting potentials. After this induction protocol, the fPS was depressed as would be expected from low-frequency stimulation (Dudek and Bear, 1992; Mulkey and Malenka, 1992) and, despite the depolarization applied during 1 $\mathrm{Hz}$ stimulation, a similar depression was apparent in the interneuron EPSP $(82.9 \pm 4.7 \%$ for fPS, $n=5, p<0.05 ; 81.6 \pm 4.5 \%$ for EPSP, $n=5, p<0.05$ ) (Fig. 2, B1,B2). However, both the fPS and interneuron EPSPs were potentiated by a subsequent tetanic stimulation $(125.7 \pm 6.8 \%$ for $\mathrm{fPS}, n=5, p<0.05$; and $161.0 \pm$ $11.0 \%$ for EPSP, $n=5, p<0.05)$. These data strongly suggest 

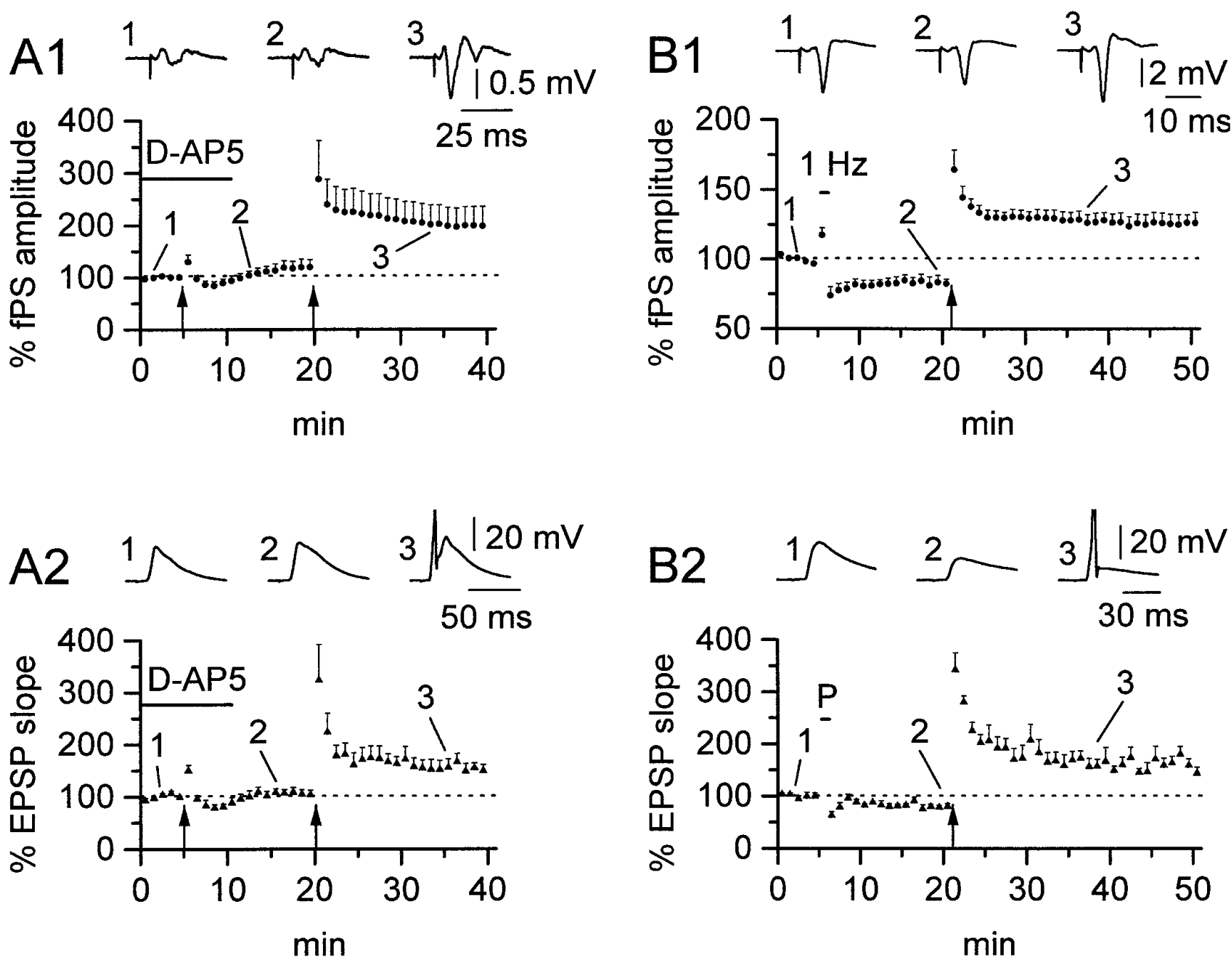

Figure 2. NMDARs are involved in passive propagation, but not in direct plasticity of horizontal OAIs. A1, Average plot showing the effect of D-AP5 $(50 \mu \mathrm{M})$ (solid bar) during tetanization (arrow) on the fPS recorded in st. pyramidale. No LTP could be elicited in the presence of the drug (117.5 \pm $14.1 \%)$, although the slices were sensitive to tetanization after washout of the blocker $(198.2 \pm 36.4 \%)$. A2, A similar result was obtained in the simultaneously recorded interneuron EPSP $(106.2 \pm 7.3 \%$ in the presence of D-AP5 vs $155.2 \pm 13.1 \%$ after washout $)$. Data from $n=6$ whole-cell experiments. Insets in $A 1$ and $A 2$ show averaged traces at the start of the experiment (1), after tetanization in the presence of the drug (2), and after tetanization in a drug-free medium (3). B1 shows the effect of the pairing and tetanus protocol on the fPS; $1 \mathrm{~Hz}$ (bar) stimulation causes depression $(82.9 \pm 4.7 \%)$ of the amplitude of the fPS, followed after tetanization (arrow), however, by potentiation $(125.7 \pm 6.8 \%)$. B2, The same protocol applied to simultaneously recorded interneurons failed to induce LTP during the pairing protocol. Despite the interneuron receiving both $1 \mathrm{~Hz}$ stimulation and depolarization, pairing $(P)$ was followed by a depression, similar to that seen in the fPS $(B 1)(81.6 \pm 4.5 \%)$. LTP could, however, be induced in the interneuron by tetanic stimulation, in parallel with potentiated fPSs $(161.0 \pm 11.0 \%)$. Data from $n=5$ perforated-patch experiments. Averaged traces are shown in $B 1$ and $B 2$ in control (1), after pairing procedure (2), and after tetanic stimulation (3).

that we are inducing LTP only on CA1 pyramidal neurons and, consequently, we are observing a passively propagated form of LTP on this class of interneurons.

Figure 3 illustrates the results obtained in experiments in which the same test protocol was applied to vertical OAIs. In cells, which displayed a clear biphasic response (4 of 6 interneurons), the initial slope of the early EPSP (EPSP ${ }_{1}$, occurring before the fPS) and the slope of the second component $\left(\mathrm{EPSP}_{2}\right)$ were examined independently. Low-frequency stimulation resulted in a depression of the fPS amplitude $(53.5 \pm 7.2 \%, n=6, p<0.05)$ as expected. Although no change in the slope of the early EPSP component occurred (99.8 \pm $5.2 \%, n=6$, NS), a clear depression of the second EPSP component was observed $(69.2 \pm 7.0 \%, n=4, p<0.05)$, in parallel with the fPS response. When subsequent tetanic stimulation was applied, the fPS amplitude was potentiated $(122.1 \pm 17.9 \%, n=6, p<0.05)$, but no significant change could be observed in the early EPSP response $(90.9 \pm 4.87 \%, n=6, \mathrm{NS})$. In contrast, a marked potentiation of the second EPSP component occurred $(117.3 \pm 13.6 \%, n=4, p<0.05)$, similar to the fPS. Moreover, the latency of detection of the second EPSP component and the fPS peak shifted in parallel, consistent with the second EPSP component being generated by the recurrent collaterals of CA1 pyramidal neurons (Fig. 3, arrows in $A 1, A 3$ for fPS and $\mathrm{EPSP}_{2}$, respectively). These results argue against a direct form of synaptic plasticity in the feedforward component, yet strongly suggest passive propagation of plasticity only in the secondary feedback component of the EPSP on vertical interneurons.

\section{St. radiatum interneurons (RIs)}

We have included in this category all cells whose soma were present in st. radiatum, although their axons innervated various 

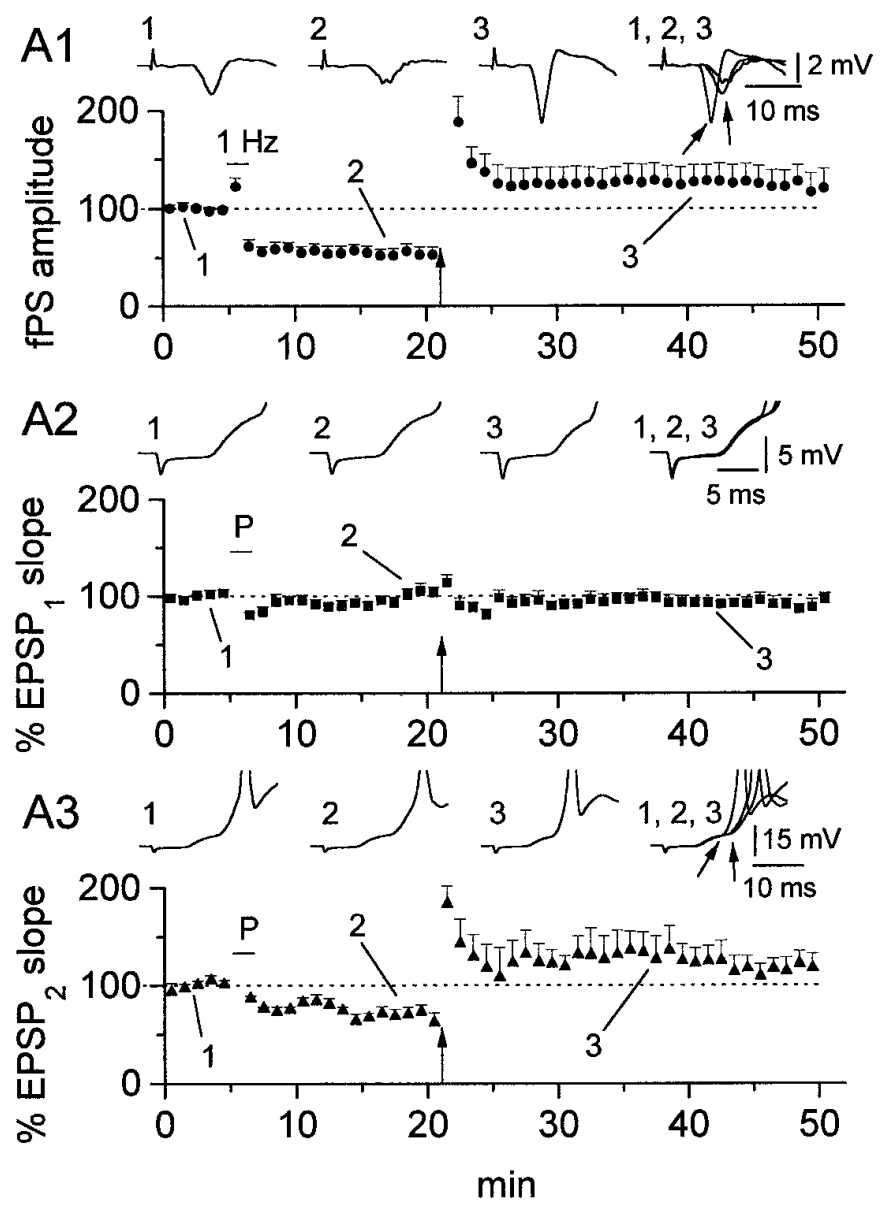

Figure 3. Passive propagation of LTP in vertical OAIs is restricted to the second component of the EPSP. Response of the st. pyramidale fPS to pairing and tetanization $(A 1)$ shows that the slices are responsive to both $1 \mathrm{~Hz}$ (bar) and tetanic (arrow) stimulation (53.5 \pm 7.2 and $122.1 \pm 17.9 \%$ after 1 and $100 \mathrm{~Hz}$, respectively). The analysis of the interneuron EPSP is shown in $A 2$ for the first and in $A 3$ for the second component. Note that changes after the LTP-inducing protocols appear only in the later component $(A 3)\left(\mathrm{EPSP}_{2}, 69.2 \pm 7.0\right.$ and $117.3 \pm 13.6 \%$ after pairing and tetani, respectively) and not in the early component $(A 2)\left(\mathrm{EPSP}_{1}, 99.8 \pm\right.$ 5.2 and $90.9 \pm 4.87 \%$ after pairing and tetani, respectively). Data from $n=$ 3 perforated-patch and $n=3$ whole-cell experiments. Insets are averaged traces in control (1), after pairing (2), after tetanization (3), and superimposed (1-3). Note also the parallel shift to the left of both the peak fPS and the onset of $\mathrm{EPSP}_{2}$ after tetanization (arrows in the insets).

regions of the CA1 subfield (e.g., Fig. $4 A 1$ ). In this class, all cells possessed similar electrophysiological properties and displayed continuous repetitive firing despite their heterogeneous morphologies. As shown in Figure $4 A 2$, these neurons responded to positive current injection with a train of nonaccommodating action potentials. A prominent sag occurred during negative electrotonic pulses, typical of anomalous rectification (Maccaferri et al., 1989). Stimulation of st. radiatum afferents elicited a synaptic response the onset of which preceded the peak of the simultaneously recorded fPS. These data are consistent with a predominant feedforward excitation of these cells (Lacaille and Schwartzkroin, 1988a; Williams et al., 1994). When the pairing and subsequent tetanus protocol was applied to these cells, no change occurred in the strength of synaptic transmission $(105.9 \pm 4.7$ and $110.6 \pm 6.7 \%$, respectively, $n=8$, NS), despite a depression of the simultaneously recorded fPS after the $1 \mathrm{~Hz}$ protocol $(79.7 \pm$
$2.2 \%, n=8, p<0.05)$ and a potentiation of the fPS after the tetanic protocol $(127.2 \pm 9.0 \%, n=8, p<0.05)$. In three of eight interneurons, although no changes were apparent on the initial slope of the EPSP, it often was possible to discern a late component of the EPSP that occurred only after tetanic stimulation, suggesting the presence of passive propagation of LTP on a population of these cells. Alternatively, the recruitment of the later component of the EPSP after tetanization simply may reflect changes elsewhere in the circuit, e.g., back propagation from CA3 and/or changes in $\mathrm{GABA}_{\mathrm{B}}$ inhibition. However, because of the lack of a clear biphasic response and/or the contamination of this component by action potential firing, we were unable to reliably quantify this observation.

\section{RGs}

Among the heterogeneous cell types in st. radiatum from which recordings were made, we frequently observed a cell type that showed stereotyped morphological and electrophysiological characteristics. We have referred to these cells as st. radiatum "giant cells" because of their extensive dendritic trees. Three of these neurons are illustrated in Figure 5 to underscore their morphological homogeneity: typically these cells possessed a large, triangular shaped cell body $(\sim 30 \mu \mathrm{m})$ with its apex directed toward st. pyramidale. The dendritic tree was extremely elaborate, branching immediately away from the cell body in two main dendritic shafts, which could extend to, and cross, the hippocampal fissure. In contrast, only a relatively restricted dendritic tree emerged from the apical end of the soma. The RG morphology closely resembles both the CA1 cells described by Lang and Frotscher (1990) (their Fig. 7b) and a cell type observed in the inferior region of the hippocampus (Amaral and Woodward, 1977) subsequently shown to be GAD-immunopositive (Woodson et al., 1989). The axons of these cells typically traversed the pyramidal cell layer and passed into st. oriens. We never observed axon ramification in the pyramidal cell layer as reported by Amaral and Woodward (1977); however, in the cell shown in Figure 5A1, an axon collateral courses along the st. pyramidale/oriens border. The electrophysiological properties of these cells were not described previously. These cells did not display spontaneous rhythmic activity, allowing determination of their resting membrane potential $(-49.8 \pm 1.0 \mathrm{mV}, n=15)$. The response to positive current injection elicited a train of action potentials with modest accommodation (Fig. 5A), whereas negative current steps induced a sag in the voltage response that, on return to rest, could give rise to a rebound burst of action potentials $(n=4)$. The onset of the evoked EPSP elicited by stimulation of st. radiatum afferents always preceded the peak of the fPS, consistent with feedforward activation of this cell type (Fig. $5 B$ ). Application of the pairing protocol to these neurons (Fig. 6) induced robust LTP. The EPSP slope increased to $161.6 \pm 14.6 \%(n=7, p<0.05)$ of control. The fPS recorded in st. pyramidale was, on the contrary, decreased to $59.2 \pm 8.5 \%(n=7, p<0.05)$. This result suggests that RGs may undergo a direct form of LTP similar to that observed in pyramidal cells. To test the NMDAR dependency of LTP induction in these cells, we performed identical experiments in the presence of D-AP5 $(25-50 \mu \mathrm{M})$. Under these conditions, no LTP could be observed (113.9 $\pm 6.9 \%, n=4$, NS), suggesting a mechanism similar to LTP induction in pyramidal cells. In fact, after washout of D-AP5, LTP could be induced by a pairing protocol in the same cells $(150.4 \pm 10.6 \%, n=4, p<0.05)$. 


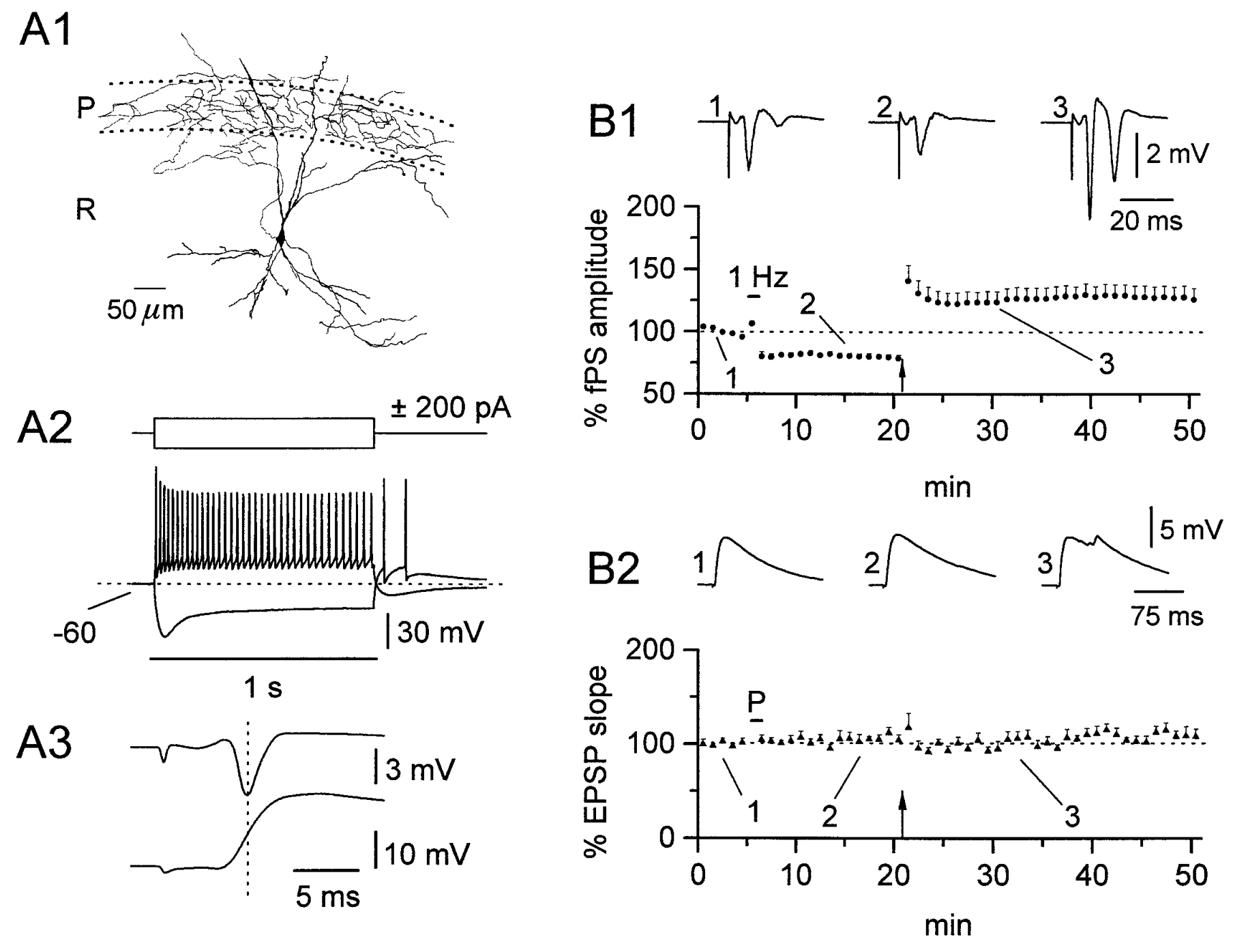

Figure 4. St. RI lack both forms of synaptic plasticity. An example of an RI is shown in $A 1$; note the selective targeting of st. pyramidale by its axon. $A 2$, RIs respond to step currents with little adaptation during positive current injection, whereas a clear sag of the voltage response was noticeable during negative current pulses. The cell was held at $-60 \mathrm{mV}$. A3, Simultaneous recording of an fPS in st. pyramidale (upper trace) and interneuron-evoked EPSP (lower trace); note that the fPS peak occurs after the onset of the interneuron EPSP ( $-2.0 \mathrm{msec})$. B1, Although the fPS shows depression of the pyramidal cell response after pairing $(1 \mathrm{~Hz} ; 79.7 \pm 2.2 \%)$ and potentiation after tetanization $($ arrow, $127.2 \pm 9.0 \%)$, the EPSP evoked in the interneurons was virtually unchanged (105.9 \pm 4.7 and $110.6 \pm 6.7 \%$, respectively). Data from $n=8$ perforated-patch experiments.

\section{DISCUSSION}

\section{LTP in OAls}

The observation that the EPSP onset of horizontal OAIs always followed the pyramidal cell fPS peak confirmed previous electrophysiological and in vivo morphological studies (Blasco-Ibáñez and Freund, 1995; Maccaferri and McBain, 1995) showing that these neurons are primarily "feedback" cells, and are not innervated by $\mathrm{CA} 3$ pyramidal neuron afferents. In these cells, tetanic stimulation induced a strictly NMDAR-dependent form of LTP that was completely prevented by application of AP5. When tested for LTP using pairing, horizontal interneurons showed a synaptic depression; however, they could be potentiated after tetanic stimulation. These results are most easily explained by the occurrence of only a pure passive propagation of synaptic plasticity onto these cells. It should be noted, however, that in these experiments, the pairing procedure tested not only for potentiation at putative synapses between Schaffer collateral-commissural fibers and the interneuron, but also at the CA1 recurrent collateralinterneuron synapse. In fact, during the $60 \mathrm{sec}$ period of $1 \mathrm{~Hz}$ stimulation, the fPS is actually increased, ensuring propagation of the stimuli from st. radiatum afferents to the horizontal interneurons via pyramidal cell firing. In this case, pairing will induce both direct LTP (if present) and, in addition, passive propagation of LTD. Therefore, any change or lack of change in the EPSP may reflect the summation of both direct LTP and indirect LTD, which could even cancel each other out. In our experiments, however, the response of horizontal OAIs to either protocol followed that of the simultaneously recorded fPS. On a quantitative level, both the fPS and OAI EPSPs demonstrated similar magnitudes of LTD, but different magnitudes of LTP. In Figure $2 A$, the amount of fPS LTP is larger than the corresponding OAI EPSP; however, the opposite observation is true for the data presented in Figure $2 B$. The quantitative differences between the fPS and EPSP plasticity may simply reflect differing magnitudes of LTP induced 
Figure 5. Basic morphological and electrophysiological characteristics of RGs. $A 1-A 3$ show camera lucida drawings from representative cells of this class. Calibration bar, $50 \mu \mathrm{m}$. Note the triangular cell body from which two main diverging dendritic shafts emerge and the axon collateral ramifying in st. oriens/alveus (arrows). $B$ shows the voltage response to current injection; a train of action potentials was elicited by positive current, whereas a depolarizing sag was apparent on negative current injection. A brief burst of action potentials was observed on the anode break. In double-recording experiments $(C)$, the onset of the EPSP preceded the onset of the peak of fPS (arrow) $(-3.8$ $\mathrm{msec}$ ), suggesting feedforward activation.
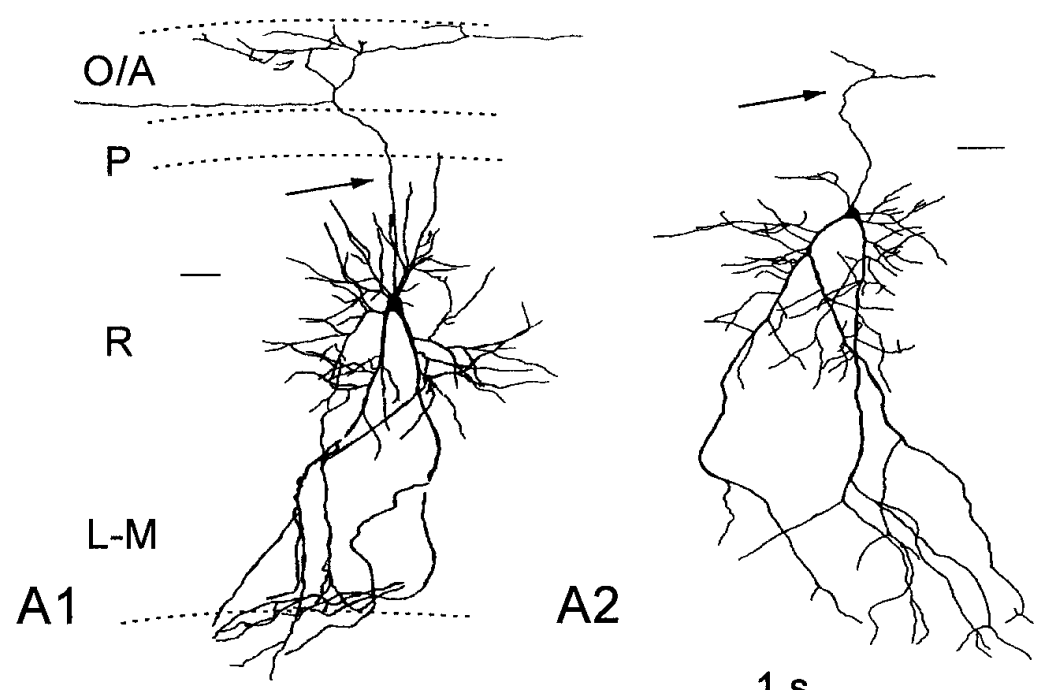

$1 \mathrm{~s}$
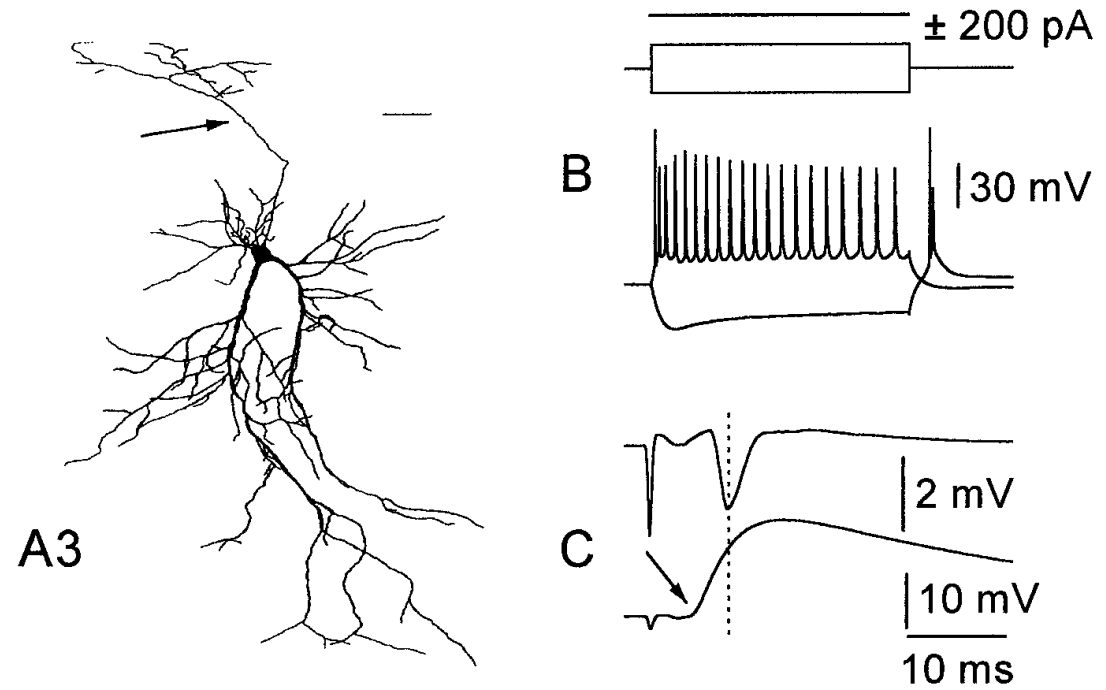

in the cells that generate fPS, compared with the actual pyramidal cells that innervate the OAI under study. Thus, the presence of direct NMDAR-dependent LTP in horizontal OAIs is very unlikely, whereas we can show the presence of a robust passive propagation mechanism.

The EPSP onset of vertical cells always preceded the fPS peak, consistent with feedforward excitation of these neurons. In $\sim 80 \%$ of cells, a biphasic EPSP was observed, with a component that preceded the fPS and a second component time locked to the peak of the fPS consistent with both feedforward and feedback excitation of these cells, in agreement with previous reports (Lacaille et al., 1987, 1989). After the pairing and tetani protocol, no significant change was detected in the first component, whereas the later component followed the fPS activity. These results argue against a direct form of LTP in vertical OAI, whereas they support a role for passive propagation, similar to horizontal cells. It is somewhat surprising that the same st. radiatum afferents that make synaptic contact with CA1 pyramidal cells, which are able to undergo synaptic plasticity, do not possess this capability at feedforward synapses onto interneurons. This may reflect either a heterogeneity of receptors on the postsynaptic membranes of interneurons or the lack of some cytoplasmic component(s) essential for the LTP cascade in these cells. Because OAIs possess the calcium binding proteins parvalbumin, calretinin, and calbindin- $\mathrm{D}_{28 \mathrm{~K}}$ (Sloviter, 1989; Toth and Freund, 1992), it is possible that $\left[\mathrm{Ca}^{2+}\right]_{\mathrm{i}}$ buffering is sufficient to prevent attainment of the induction threshold for synaptic plasticity. This hypothesis is unlikely, however, because it presumes the existence of adequate LTP-inducing machinery in a nonpermissive environment. Alternatively, we would favor the lack of some of the necessary components required for LTP induction. Our results contrast to those reported by Ouardouz and Lacaille (1995), who reported LTP in an unidentified st. oriens cell type. In these studies, tetanic stimulation was used to induce LTP, which does not allow a clear distinction between direct plasticity and passive propagation. In their study, however, the use of BAPTA-loaded electrodes prevented induction of LTP in OAIs, suggesting that a direct form of cellular LTP was indeed present. However, in these experiments the authors did not monitor the extracellular pyramidal fPS as a positive control to confirm that plasticity actually did occur in the slices used for these experiments (Mulkey and Malenka, 1992). At this time, it is difficult to explain the discrepancies between their experiments and the present data. We cannot rule out, however, the possibility that other morphologically distinct interneurons in st. oriens/alveus display plastic properties. 

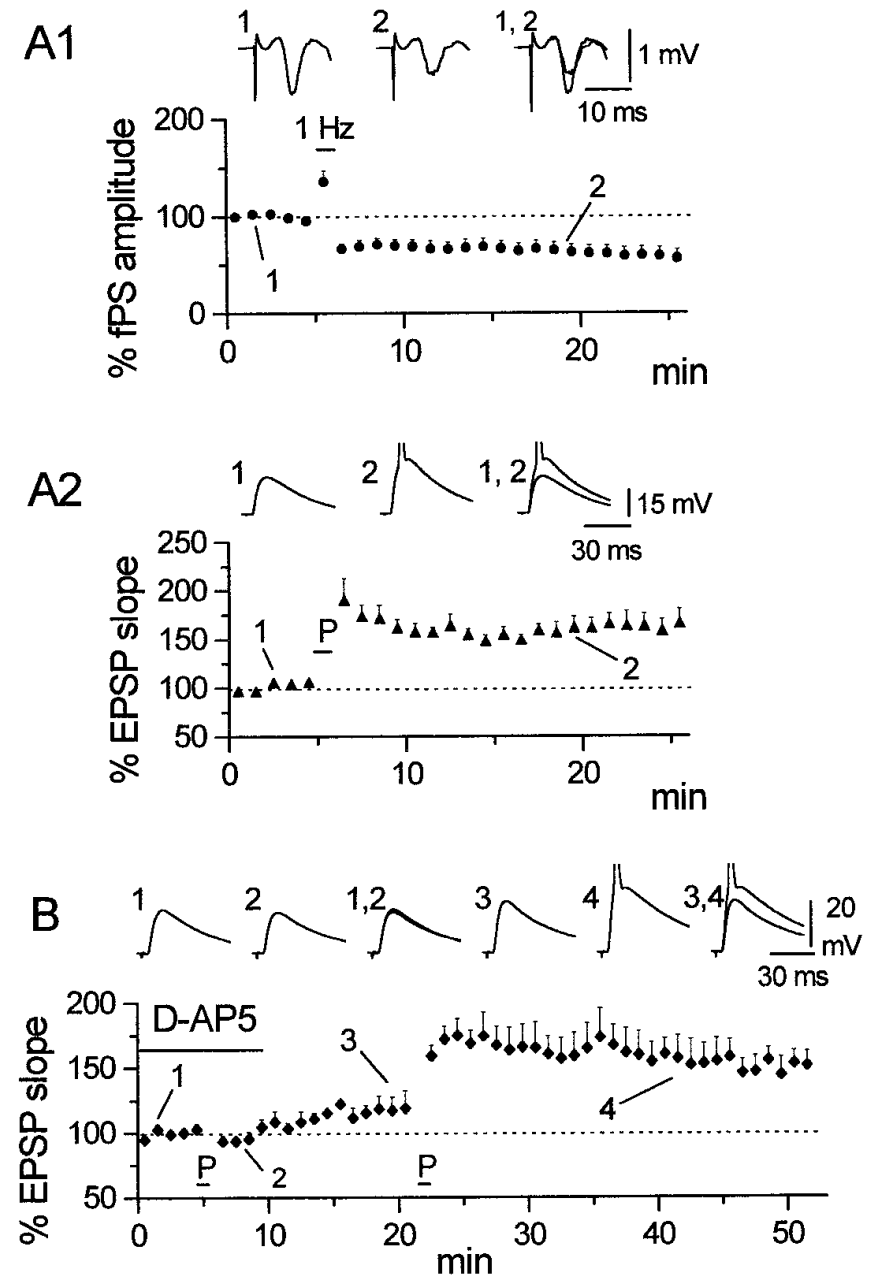

Figure 6. The induction of LTP in RGs is NMDAR-dependent. Although a depression of the amplitude of fPSs followed the pairing procedure $(A 1)(59.2 \pm 8.5 \%)$, the simultaneously recorded EPSP from single RGs was potentiated $(A 2)(161.6 \pm 14.6 \%)$. Data from $n=3$ perforatedpatch and $n=4$ whole-cell experiments. In the presence of D-AP5 (25-50 $\mu \mathrm{M})$ (bar in $B)$, LTP was prevented $(B)(113.9 \pm 6.86 \%)$, but was induced after washout of the drug $(150.4 \pm 10.6 \% ; n=4$ perforated-patch experiments). Insets in $A 1$ and $A 2$ are averaged traces before (1), after the pairing procedure $(2)$, and superimposed $(1,2)$. Insets in $C$ represent averaged traces before (1), after pairing (2), and superimposed $(1,2)$ in the presence of D-AP5, and before (3), after pairing (4), and superimposed $(3,4)$ after washout of D-AP5.

\section{LTP in st. RIs}

RIs represent a heterogeneous category of cells, and although several studies have documented their different morphologies and axonal targets (Schlander and Frotscher, 1986; Lacaille and Schwartzkroin, 1988a; McBain et al., 1992; McBain and Dingledine, 1993; Valtschanoff et al., 1993; Williams et al., 1994; Khazipov et al., 1995), no classification of these cells exists. In marked contrast to the properties of the CA3-CA1 pyramidal cell synapses (Bliss and Collingridge, 1993), stimulation of the same Schaffer-collateral afferents by either a pairing or tetanus protocol failed to induce any form of synaptic plasticity. It is important to note that despite the lack of any direct interneuron plasticity, the simultaneously recorded fPS in st. pyramidale responded to both $1 \mathrm{~Hz}$ and tetanic stimulation with depression and potentiation, respectively. These results are in agreement with those reported by Ouardouz and Lacaille (1995). In experiments designed to reveal subtle plastic changes, we compared the response with the pairing induction protocol in cells recorded in the presence and absence of AP5, both these cells and vertical OAIs showed a total lack of direct LTP (data not shown).

\section{LTP in RGs}

Woodson et al. (1989) reported that $\sim 90 \%$ of cells for which the somata lie outside st. pyramidale show GAD- or GABAimmunoreactivity. However, pyramidal neurons whose cell bodies are ectopically located out of the pyramidal cell layer are known to exist in both st. radiatum and oriens (Ramon y Cajal, 1911). The response of RGs to current injection was clearly different to that observed in RIs. Although depolarizing current injection always elicited a train of action potentials, the degree of accommodation was usually larger than that observed in RIs. The absence of spontaneous action potential activity and presence of spike accommodation suggests that although RGs may represent a subclass of st. radiatum inhibitory interneurons, we cannot eliminate the possibility that these cells are simply ectopically located pyramidal cells. Given the ambiguous nature of these cells, we are at present undertaking a detailed morphological and electron microscopic study of these neurons to clarify the issue. The confinement of their dendritic trees to st. radiatum/lacunosum/moleculare and synaptic responses that preceded the peak of the fPS suggest that this cell type is primarily innervated by feedforward afferents.

The giant-cell of st. radiatum was the only cell type tested that responded with potentiation to the pairing protocol. As discussed previously, induction of LTP by a pairing protocol is unequivocal evidence for direct LTP. Whereas the fPS was decreased after the $1 \mathrm{~Hz}$ stimulation, the EPSP recorded from the RG was potentiated, establishing that these cells possess a direct form of LTP. Even if the EPSP was contaminated by the passive propagation of plasticity from pyramidal cells, this cannot account for the observed potentiation, because pyramidal cells were depressed after the $1 \mathrm{~Hz}$ stimulation. Because the induction of LTP in these cells was blocked by the NMDAR antagonist D-AP5, these data suggest that this class of st. radiatum cells possess mechanisms of LTP induction similar to CA1 pyramidal cells.

\section{LTP in interneurons and network effects}

Our results provide clear evidence for a heterogeneity of plasticity among different classes of nonpyramidal neuron using both pairing and tetanic induction protocols. Our data do not rule out, however, the existence of other forms of synaptic plasticity in interneurons that can be induced by other stimulus paradigms. Considering the precision and variability of axonal targeting from interneurons to different regions of pyramidal cell dendritic tree (Gulyás et al., 1993; Sik et al., 1995), our data suggest that the network properties of the hippocampal CA1 region will be strongly and selectively influenced by induction of synaptic plasticity. Horizontal OAIs innervate almost selectively st. lacunosum/ moleculare and modulate activity between the temporoammonic pathway inputs and the CA1 pyramidal cell apical dendrites (Maccaferri and McBain, 1995). The reciprocal interplay between LTP and LTD on these cells likely will influence the information flow from the entorhinal cortex into the intrinsic hippocampal circuitry. In contrast, the main axonal target of vertical OAIs lies in both the pyramidal cell (McBain et al., 1994) and dendritic layers of CA1 (Lacaille et al., 1987; Sik et al., 1995). Excitation of this class of interneurons may therefore prevent the generation of sodium or calcium spikes, initiated at the axon hillock or dendrites of pyramidal cells, respectively (Stuart and Sakmann, 1994; Miles 
et al., 1996). The weight of the inhibitory role played by these interneurons will be strongly influenced by activity from the CA1 pyramidal cell recurrent collaterals and will be further intensified after induction of LTP in CA1 pyramidal neurons. This form of inhibition may be important in preventing multiple spike discharges or epileptiform activity induced by synaptic activation of pyramidal cells after establishment of LTP. In this scenario, after LTP induction, the interplay between a potentiated EPSP, which will facilitate pyramidal cell firing, and the consequent passive propagation of LTP onto a vertical OAI will result in a potentiation of a late IPSP component onto pyramidal neurons, which may act to prevent the occurrence of prolonged spike discharges. However, it has been shown previously that even when interneuron afferents demonstrate LTP, the IPSP onto pyramidal cells could be depressed postsynaptically (Morishita and Sastry, 1991; Xie and Sastry 1991; Stelzer et al., 1994), adding another level of complexity to the network effects of LTP induction.

The lack of LTP in RIs suggests a certain degree of stability in feedforward inhibition during synaptic plasticity. Interestingly, however, we have found synaptic plasticity in a different class of st. radiatum cells. At this time, the precise targets of these cells (either pyramidal and/or interneuronal) are undetermined, making it impossible to assign a role for these cells and how their potentiation may impact the hippocampal network. Electron microscopy studies are required to determine the precise nature of their synaptic contacts.

In conclusion, as investigations into LTP continue to shed light on the molecular cascade of events responsible for its induction in pyramidal cells, the combination of these analyses with studies on network effects of plasticity on different cells types will allow us to obtain a more complete picture of synaptic plasticity in the entire hippocampus.

\section{REFERENCES}

Amaral DG, Woodward DJ (1977) A hippocampal interneuron observed in the inferior region. Brain Res 124:225-236.

Blanton MG, LoTurco JJ, Kriegstein AR (1989) Whole-cell recordings from neurons in slices of reptilian and mammalian cerebral cortex. J Neurosci Methods 30:203-210.

Blasco-Ibáñez JM, Freund TF (1995) Synaptic input of horizontal interneurons in stratum oriens of the hippocampal CA1 subfield: structural basis of feed-back activation. Eur J Neurosci 7:2170-2180.

Bliss TVP, Collingridge GL (1993) A synaptic model of memory: longterm potentiation in the hippocampus. Nature 361:31-39.

Buhl EH, Halasy K, Somogyi P (1994) Diverse source of hippocampal unitary inhibitory postsynaptic potentials and the number of synaptic release sites. Nature 368:823-828.

Buzsaki G, Eidelberg E (1982) Direct afferent excitation and long-term potentiation of hippocampal interneurons. J Neurophysiol 48:597-607.

Clark K, Collingridge GL (1995) Synaptic potentiation of dualcomponent excitatory postsynaptic currents in the rat hippocampus. J Physiol (Lond) 482:39-52.

Cobb SR, Buhl EH, Halasy K, Paulsen O, Somogyi P (1995) Synchronization of neuronal-activity in hippocampus by individual GABAergic interneurons. Nature 378:75-78.

Collingridge GL, Kehl SJ, McLennan H (1983) Excitatory amino acids in synaptic transmission in the Schaffer collateral-commissural pathway of the rat hippocampus. J Physiol (Lond) 334:33-46.

Dudek SM, Bear MF (1992) Homosynaptic long-term depression in area CA1 of hippocampus and the effects of NMDA receptor blockade. Proc Natl Acad Sci USA 89:4363-4367.

Edwards FA, Konnerth A, Sakmann B, Takahashi T (1989) A thin slice preparation for patch clamp recording from synaptically connected neurones of the mammalian central nervous system. Pflügers Arch 414:600-612.

Freund TF, Buzsaki G (1996) Interneurons of the hippocampus. Hippocampus, in press.
Gulyás AI, Miles R, Hájos N, Freund TF (1993) Precision and variability in postsynaptic target selection of inhibitory cells in the hippocampal CA3 region. Eur J Neurosci 5:1729-1751.

Gustafsson B, Wigstrom H, Abraham WC, Huang YY (1987) Long-term potentiation in the hippocampus using depolarizing current pulses as the conditioning stimulus to single volley synaptic potentials. J Neurosci 7:774-780.

Hamill OP, Marty A, Neher E, Sakmann B, Sigworth FJ (1981) Improved patch-clamp techniques for high resolution current recordings from cells and cell-free patches. Pflügers Arch 391:85-100.

Isaac JTR, Nicoll RA, Malenka RC (1995) Evidence for silent synapses: implications for the expression of LTP. Neuron 15:427-434.

Kato K, Clifford DB, Zorumski CF (1993) Long-term potentiation during whole-cell recording in rat hippocampal slices. Neuroscience 53:39-47.

Khazipov R, Congar P, Ben-Ari Y (1995) Hippocampal CA1 lacunosummoleculare interneurons: modulation of monosynaptic GABAergic IPSCs by presynaptic GABA G $_{\mathrm{B}}$ receptors. J Neurophysiol 74:2126-2137.

Korn SJ, Marty A, Connor JA, Horn R (1991) Perforated patch recording. J Neurosci Methods 4:264-373.

Kullmann DM, Siegelbaum SA (1995) The site of expression of NMDA receptor-dependent LTP: new fuel for an old fire. Neuron 15:997-1002.

Kyrozis A, Reichling DB (1995) Perforated-patch recording with gramicidin avoids artifactual changes in intracellular chloride concentration. J Neurosci Methods 57:27-35.

Lacaille JC, Schwartzkroin PA (1988a) Stratum lacunosum-moleculare interneurons of hippocampal CA1 region. I. Intracellular response characteristics, synaptic responses and morphology. J Neurosci 8:1400-1410.

Lacaille JC, Schwartzkroin PA (1988b) Stratum lacunosum-moleculare interneurons of hippocampal CA1 region. II. Intrasomatic and intradendritic recordings of local circuit synaptic interactions. J Neurosci 8:1411-1424.

Lacaille JC, Mueller AL, Kunkel DD, Schwartzkroin PA (1987) Local circuit interaction between oriens/alveus interneurons and CA1 pyramidal cells in hippocampal slices: electrophysiology and morphology. J Neurosci 7:1979-1993.

Lacaille JC, Kunkel DD, Schwartzkroin PA (1989) Electrophysiological and morphological characterization of hippocampal interneurons. In: The hippocampus - new vistas (Chan-Palay V, Köhler C, eds), pp 287305. New York: Liss.

Lang U, Frotscher M (1990) Postnatal development of nonpyramidal neurons in the rat hippocampus (areas CA1 and CA3): a combined Golgi/electron microscope study. Anat Embryol (Berl) 181:533-545.

Liao D, Hessler NA, Malinow R (1995) Activation of postsynaptically silent synapses during pairing-induced LTP in CA1 region of hippocampal slice. Nature 375:400-404.

Lisman J (1994) The CaM kinase II hypothesis for the storage of synaptic memory. Trends Neurosci 17:406-412.

Maccaferri G, McBain CJ (1995) Passive propagation of LTD to stratum oriens-alveus inhibitory neurons modulates the temporoammonic input to the hippocampal CA1 region. Neuron 15:135-145.

Maccaferri G, Mangoni M, Lazzari A, DiFrancesco D (1989) Properties of the hyperpolarization-activated current $\left(\mathrm{I}_{\mathrm{h}}\right)$ in rat CA1 pyramidal cells. J Neurophysiol 69:2129-2136.

Malenka RC (1994) Synaptic plasticity in the hippocampus: LTP and LTD. Cell 78:535-536.

Malenka RC, Nicoll RA (1993) NMDA-receptor-dependent synaptic plasticity: multiple forms and mechanisms. Trends Neurosci 16:521-527.

Malenka RC, Kauer JA, Zucker R, Nicoll RA (1988) Postsynaptic calcium is sufficient for potentiation of the hippocampal synaptic transmission. Science 242:81-83.

Malenka RC, Kauer JA, Perkel DJ, Mauk MD, Kelly PT, Nicoll RA, Waxham MN (1989) An essential role for postsynaptic calmodulin and protein kinase activity in long-term potentiation. Nature 340:554-557.

Malinow R (1991) Transmission between pairs of hippocampal slice neurons: quantal levels, oscillations and LTP. Science 252:722-724.

Malinow R, Tsien RW (1990) Presynaptic enhancement revealed by whole-cell recordings of long-term potentiation in rat hippocampal slices. Nature 346:177-180.

Malinow R, Madison DV, Tsien RW (1988) Persistent protein kinase activity underlying long-term potentiation. Nature 335:820-824.

Mayer ML, Westbrook GL, Guthrie PB (1984) Voltage-dependent block by $\mathrm{Mg}^{2+}$ of NMDA responses in spinal cord neurones. Nature 309:261-263. 
McBain CJ, Dingledine R (1993) Heterogeneity of synaptic glutamate receptors on CA3 st. radiatum interneurones of rat hippocampus. J Physiol (Lond) 462:373-392.

McBain CJ, Eaton JV, Brown T, Dingledine R (1992) CNQX increases spontaneous inhibitory input to CA3 pyramidal neurones in neonatal rat hippocampal slices. Brain Res 592:255-260.

McBain CJ, DiChiara TJ, Kauer JA (1994) Activation of metabotropic glutamate receptors differentially affects two classes of hippocampal interneurons and potentiates excitatory synaptic transmission. J Neurosci $14: 4433-4445$.

Miles R, Toth K, Gulyas AI, Hajos N, Freund TF (1996) Differences between somatic and dendritic inhibition in the hippocampus. Neuron 16:815-823.

Morishita W, Sastry BR (1991) Chelation of postsynaptic $\mathrm{Ca}^{2+}$ facilitates long-term potentiation of hippocampal IPSPs. NeuroReport 2:533-536.

Mulkey RM, Malenka RC (1992) Mechanisms underlying induction of homosynaptic long-term depression in area CA1 of the hippocampus. Neuron 9:967-975.

Mulkey RM, Herron CE, Malenka RC (1993) An essential role for protein phosphatases in hippocampal long-term depression. Science 261:1051-1055.

Nowak L, Bregestovski P, Ascher P, Herbet A, Prochiantz A (1984) Magnesium gates glutamate-activated channels in mouse central neurones. Nature 307:462-465.

Ouardouz M, Lacaille JC (1995) Mechanisms of selective long-term potentiation of EPSCs in interneurons of stratum oriens in rat hippocampal slices. J Neurophysiol 73:810-819.

Perouansky M, Yaari Y (1993) Kinetic properties of NMDA receptormediated synaptic currents in rat hippocampal pyramidal cells versus interneurones. J Physiol (Lond) 465:223-244.

Ramon y Cajal S (1911) Histology of the nervous system. American translation 1995. Oxford: Oxford UP.

Sah P, Hestrin S, Nicoll RA (1990) Properties of excitatory postsynaptic currents recorded in vitro from rat hippocampal interneurones. J Physiol (Lond) 430:605-616.

Schlander M, Frotscher M (1986) Non-pyramidal neurons in the guinea pig hippocampus: a combined Golgi-electron microscope study. Anat Embryol 174:35-47.
Schuman EM, Madison DV (1994) Locally distributed synaptic potentiation in the hippocampus. Science 263:532-536.

Sik A, Ylinen A, Penttonen M, Buzsáki G (1994) Inhibitory CA1-CA3hilar region feedback in the hippocampus. Science 265:1722-1724.

Sik A, Penttonen M, Ylienen A, Buzsaki G (1995) Hippocampal CA1 interneurons: an in vivo intracellular labeling study. J Neurosci 15:6651-6665.

Sloviter R (1989) Calcium-binding protein (calbindin- $\mathrm{D}_{28 \mathrm{k}}$ ) and parvalbumin immunocytochemistry: localization in the rat hippocampus with specific reference to the selective vulnerability of hippocampal neurons to seizure activity. J Comp Neurol 280:183-196.

Stelzer A, Simon G, Kovacs G, Rai R (1994) Synaptic disinhibition during maintenance of long-term potentiation in the CA1 hippocampal subfield. Proc Natl Acad Sci USA 91:3058-3062.

Stuart GJ, Sakmann B (1994) Active propagation of somatic action potentials into neocortical pyramidal cell dendrites. Nature 367:69-72.

Taube JS, Schwartzkroin PA (1987) Intracellular recording from hippocampal CA1 interneurons before and after the development of longterm potentiation. Brain Res 419:32-38.

Toth K, Freund TF (1992) Calbindin $\mathrm{D}_{28 \mathrm{k}}$-containing nonpyramidal cells in the rat hippocampus: their immunoreactivity for GABA and projection to the medial septum. Neuroscience 49:793-805.

Valtschanoff JG, Weinberg RJ, Kharazia VN, Nakane M, Schmidt HHW (1993) Neurons in rat hippocampus that synthesize nitric oxide. J Comp Neurol 331:111-121.

Williams S, Samulack DD, Beaulieu C, Lacaille JC (1994) Membrane properties and synaptic responses of interneurons located near the stratum lacunosum-moleculare/radiatum border of area CA1 in whole-cell recordings from rat hippocampal slices. J Neurophysiol 71:2217-2235.

Woodson W, Nitecka L, Ben-Ari Y (1989) Organization of the GABAergic system in the rat hippocampal formation: a quantitative immunocytochemical study. J Comp Neurol 280:254-271.

Xie Z, Sastry BR (1991) Inhibition of protein kinase activity enhances long-term potentiation of hippocampal IPSPs. NeuroReport 2:389-391.

Zhang L, McBain CJ (1995) Voltage-gated potassium currents in stratum oriens-alveus inhibitory neurons of the rat CA1 hippocampus. J Physiol (Lond) 488:647-660. 